\title{
Analysing Sound Environment and Architectural Characteristics of Libraries through Indoor Soundscape Framework
}

\author{
Papatya Nur DOKMECI YORUKOGLU ${ }^{(1),(2)}$, Jian KANG(1) \\ (1) School of Architecture, University of Sheffield \\ Sheffield, UK; e-mail: papatya@cankaya.edu.tr, j.kang@sheffield.edu.tr \\ (2) Department of Interior Architecture, Cankaya University \\ Ankara, Turkey \\ (received August 12, 2015; accepted January 4, 2016)
}

\begin{abstract}
This study presents the indoor soundscape framework in detail by describing the variables and factors that form an indoor soundscape study. The main objective is to introduce a new indoor soundscaping framework and systematically explain the variables that contribute to the overall evaluation of an indoor soundscape. Hence, the dependencies of physical and psychoacoustical factors of the sound environment and the spatial factors of the built entity are statistically tested. The new indoor soundscaping framework leads to an overarching evaluation perspective of enclosed sound environments, combining objective room acoustics research and noise control engineering with architectural analysis. Therefore, it is hypothesised that case spaces with certain plan organisations, volumetric relations, and spatial referencing lead to differentiated sound pressure level (SPL) and loudness $(\mathrm{N})$ values. SPL and N parametric variances of the sound environments are discussed through the statistical findings with respect to the architectural characteristics of each library case space. The results show that the relation between crowd level variances and sound environment parametric values is statistically significant. It is also found that increasing the atrium height and atrium void volume, the atrium's presence as a common architectural element, and its interpenetrating reference and domain containment results in unwanted variances and acoustic formations, leading to high SPL and N values.
\end{abstract}

Keywords: soundscape framework; indoor space soundscaping; indoor sound environment; spatial analysis; archi-acoustical characteristics; library; architectural analysis.

\section{Introduction}

The study of indoor soundscapes has evolved through different approaches, mainly concentrating on the study of acoustic environments, architectural characteristics, and human perception. This integrative research field, initially called as "soundscape", has been studied in the literature since the 1970s, when it was first discussed as part of the World Soundscape Project (1978) and expanded through studies by the pioneers, SCHAFFER (1994) and TRAUX (2001). Soundscape studies aim to acknowledge sounds as resources rather than waste and bring a new understanding to the research field of noise control. In soundscape studies, sound sources and overall sonic composition are considered to be important additions to the characteristics of the whole environment. Through that perspective, factors that form the overall sound environ- ment and the subjective reactions given to that experienced sound environment are studied to create pleasant and preferred soundscapes. However, noise control studies that combine noise mapping techniques focus mainly on identifying the acoustic problem using objective parametric measures, most dominantly equivalent sound pressure level in A-weighted decibels $\left(L_{e q A}\right)$. It is also stated in the literature that A-weighted sound pressure level alone is not sufficient for an overall sound environment analysis or assessment. Therefore, the loudness parameter enters the picture with its orientation and integration of the correctness factors through the human hearing perspective.

Many studies on urban and suburban soundscapes (Liu et al., 2014; Bernat, 2013; Traux, Barrett, 2011) have concentrated on identifying the acoustical problems from the users' point of view and support- 
ing their subjective findings through objective parametric measurements; however, the indoor soundscape approach has recently emerged in the literature with similar yet enhanced analysis models. The first and most important key factor for indoor soundscaping to be different from urban/open scale soundscaping is the integration of the built entity variable, which specifies the assessment of architectural characteristics. This main difference places "indoor soundscaping research" between two main acoustic fields: urban soundscape research and architectural/room acoustics research. Therefore, the indoor soundscape methodology acknowledges different approaches because it collates methods and techniques from both research areas to form its own study framework.

In studies that focus on indoor soundscapes, the function and usage of a space and its physical conditions and spatial characteristics are as important as the objective analysis and the subjective evaluation of the sound and overall environment. Spatial characteristics play a particularly key role in the sound and its formation in an enclosure that is closely linked with the building acoustics and related research fields. Therefore, an analysis of architectural totality and characteristics of an indoor space is crucial for an indoor soundscape study. The built-entity evaluations of the case spaces considered in this study are conducted through certain dissolution and analysis techniques and architectural theories that were previously reviewed and presented (DOKMECI, 2013).

Through this perspective, this study first aims to present an indoor soundscape framework that can be applicable to soundscape research conducted in enclosed environments. Therefore, the variables of the indoor soundscape framework and each related factor are explained in detail. Second, it aims to systematically relate the chosen factors of the sound environment with the built entity variables to demonstrate the dependencies and relations between the experimented factors using statistical tests. Sound recordings are used to analyse the parametric values of sound pressure level (SPL) and loudness $(\mathrm{N})$, and architectural analysis techniques and theories are combined for the evaluation of the chosen case library spaces. The objective of this study is to test and understand the dependency tendencies of the sound environment on the built entity and how the objective parametric values show variance according to the changing architectural and spatial characteristics.

\section{Indoor soundscape framework}

The first step in designing the framework of indoor soundscaping research is presented in Fig. 1. This framework could potentially be applied to the study of indoor soundscaping in enclosed spaces classified as civil, private, public, or commercial built entities following the standards and measurement procedures that are identified in the building acoustics research field. The main difference between indoor soundscaping and urban/open scale soundscaping lies in the "architecture" factor; therefore, the framework has a detailed integration of the architectural aspects and building acoustics theories. The term "indoor" addresses a space as being enclosed by defined walls,

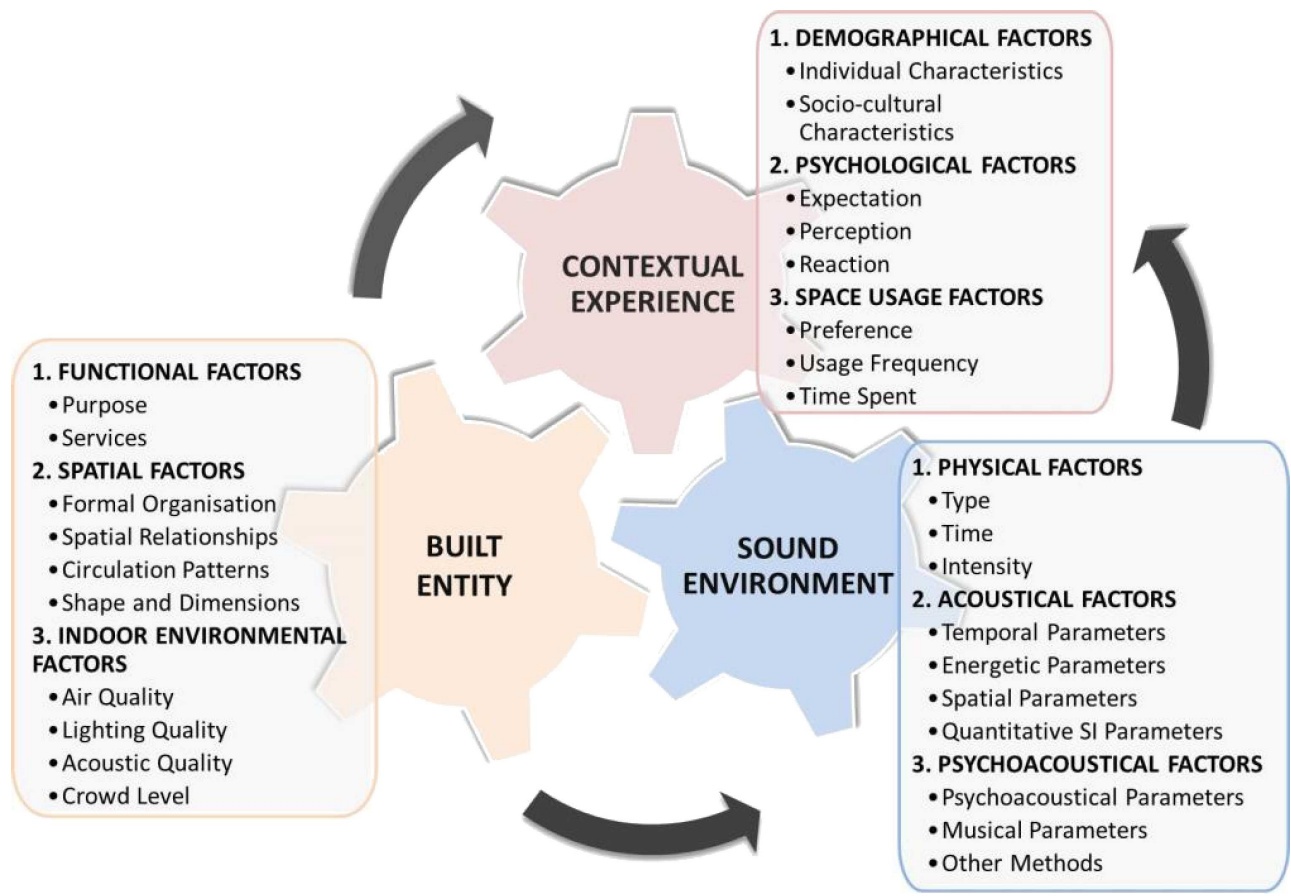

Fig. 1. Collaborative system wheel of indoor soundscaping framework with the three main variables and nine related factors. 
floor, and ceiling. Spatial characteristics play a particularly significant role for sound and its formation in an enclosure. Whilst architectural/room acoustics research considers theories developed through previous studies, indoor soundscaping builds on these findings to develop a new understanding through the soundscape approach in which space, context, and users are as important as the sound itself.

The first variable of this system to be considered is an architectural assessment of the built entity, which comprises function factors (DOVEY, 1999; Hillier, Hanson, 1984; Lawson, 2001; Pearson, RICHARDS, 1994; TUAN, 1977), indoor environmental factors (CEN, 2007; ISO, 2006), and spatial factors (ARNHEIM, 1977; CHING, 1996; VAN DER LAAN, 1983; Meiss, 1990; NorberG-Schulz, 1971; Unwin, 2003) that are created through integration of previous research and theories. In studies focusing on enclosures, the architectural assessment of an enclosure directly relates to the acoustic formations, which have a significant effect on the soundscape. Therefore, the architectural assessment of the built entity is an important aspect of indoor soundscape research that should be addressed before drawing any conclusions regarding the acoustic characteristics and the user's perception and experience in the enclosed environment.

Second, indoor soundscape studies should also focus on an objective analysis of the sound environment, which includes physical factors (BARKANA, UzKEnT, 2011; BROWN et al., 2011), acoustical factors (BotTeldooren et al., 2006; Bradley, 2011; Thomas et al., 2011; YANG, KAnG, 2011), and psychoacoustical factors (GENUIT, FiEBIG, 2006; Rychtáriková, Vermeir, 2011; Zwicker, FAstl, 1999) that are identified separately in related studies. The objective analysis of these elements should involve separate assessments using several different parameters to understand sound and how the sound environment can be perceived as a pleasant soundscape.
The third and final variable is the subjective assessment of the users' habitual and functional characteristics within the enclosed environments. This variable includes the contextual experience of the users and includes demographic, space usage, and psychological factors (BRUCE et al., 2009; HANDEL, 1989; MoORE, 1997; HATFIELD et al., 2006). Integrated and sequential study of these three variables with regard to the enclosed soundscape is the key to clearly understand the indoor soundscaping approach (DÖKMECI, KANG, 2010).

Therefore, the final framework for indoor soundscape research incorporates the three main "variables" - (1) built entity, (2) sound environment, and (3) contextual experience - and nine associated "factors" (1a) function, (1b) indoor environment, (1c) space; (2a) physics, (2b) acoustics, (2c) psychoacoustics; (3a) demographics, (3b) space usage, and (3c) psychology - which are used to explore each variable in developing the indoor soundscaping framework as presented in Fig. 1. These factors are derived from the analysis of the three main variables and are interdependent. The integration of the three variables of indoor soundscaping is accomplished by reviewing and aggregating the previous research and theories in the literature in combination with the formation of the main collaborative system.

For this study, the two previously introduced variables, (1) built entity and (2) sound environment of the indoor soundscape framework, are identified. As shown in Fig. 2 and Fig. 3, the highlighted aspects under function, spatial and indoor environmental factors of the built entity variable and the highlighted parameters under the physical and psychoacoustical factors of the sound environment variable are considered for this study. The relationship and correlations among these aspects and parameters under each identified factor between the two variables compose the core of this study.

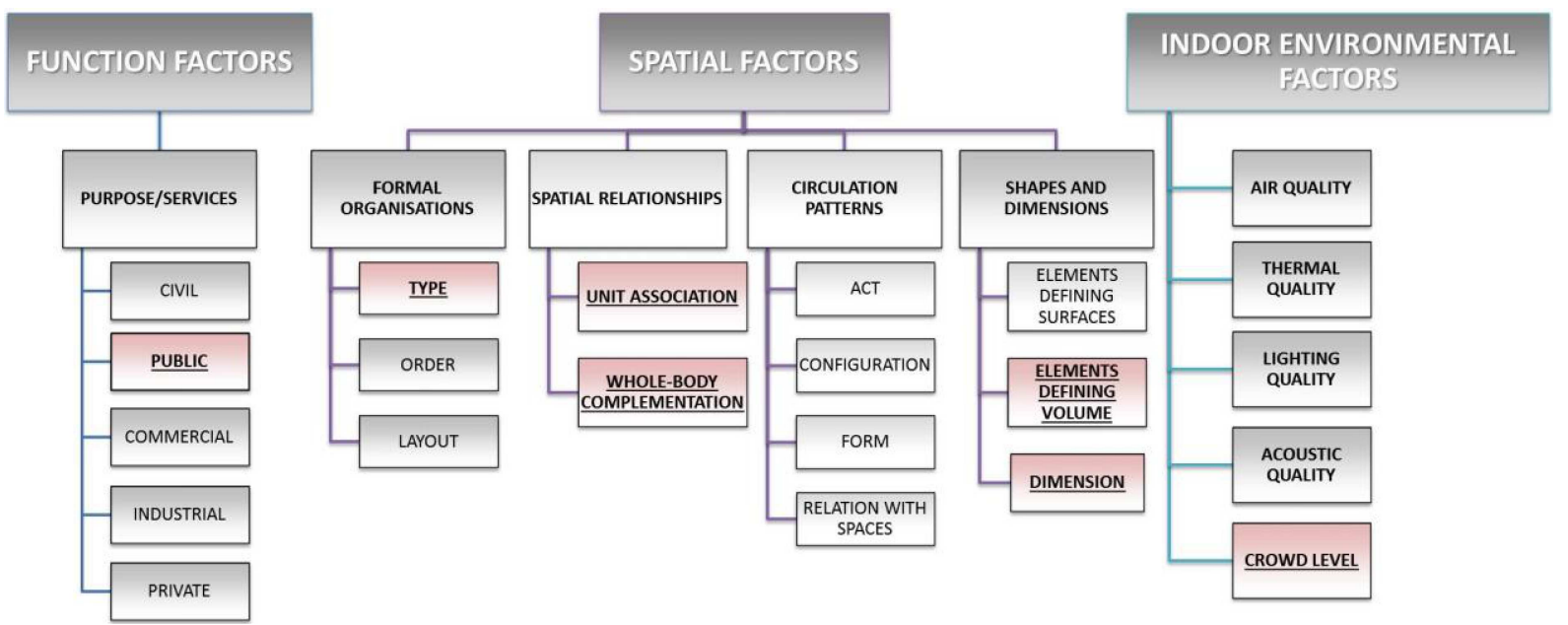

Fig. 2. Factors among the built entity variable and the highlighted aspects considered for this study. 


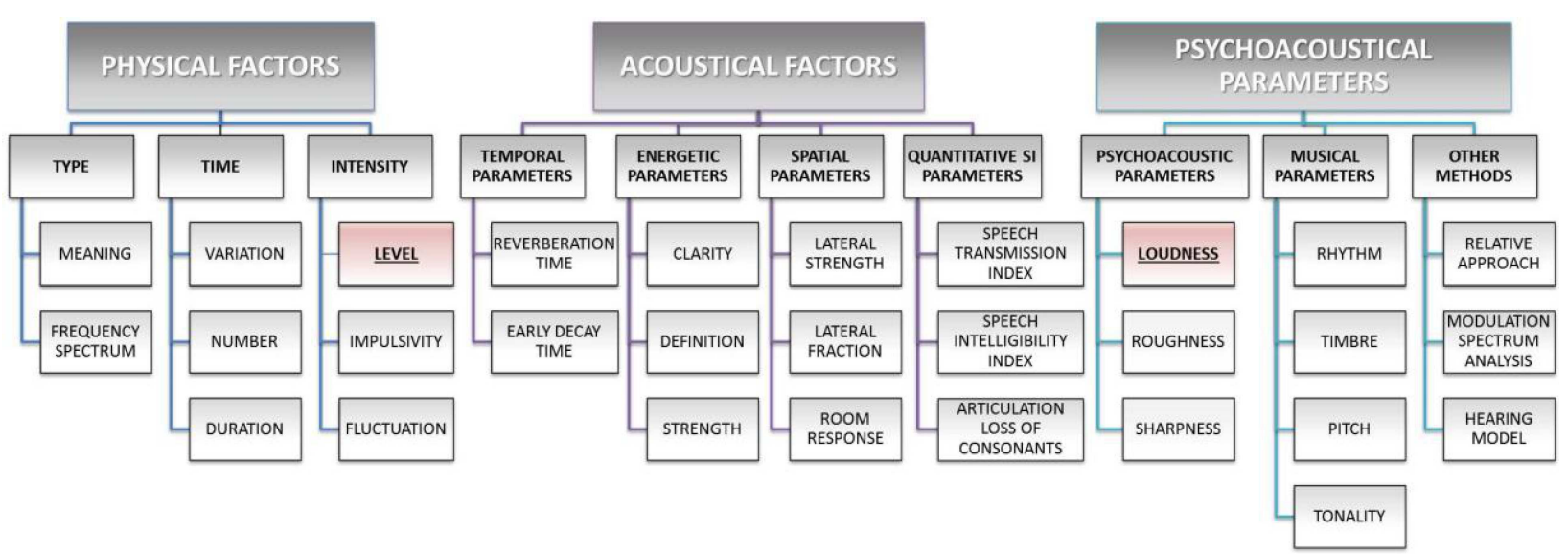

Fig. 3. Factors among the sound environment variable and the highlighted parameters considered for this study.

\section{Sound environment and built entity factors of case study sites}

Objective analysis of the recorded sound samples and architectural analysis through the combined architectural theories are the two methods used for the evaluation of the chosen case spaces and their sound environment.

\subsection{Selection of the case study sites}

Public spaces in the built environment that are classified as "libraries" as their primary function are considered for this study. The review of the architectural characteristics of the three university libraries is based on the previously presented indoor soundscape framework and built entity factors (DÖKMECI, KANG, 2010). These three different university libraries with comparable architectural characteristics are Western Bank Library (abbreviated as WB), Information Commons Library (abbreviated as IC), and St. George's Library (abbreviated as SG) located in the city of Sheffield, UK. The main user profiles of these libraries do not show great variance. The users are all university students or researchers. The data collection through sound recordings focuses on the similar functional areas in each case library. The main foyer areas in each library were used for the measurements to design a stable discussion point from an architectural perspective.

The classification of the architectural analysis, presented in Fig. 2, is considered. The three main aspects - (1) the formal organisation of the layout in a more two-dimensional approach, (2) the spatial relationships among neighbouring voids and solids in three dimensions, and (3) the circulation patterns that dominate the usage of spaces within the enclosure - are analysed for each case space. In addition, other related spatial information is included, such as the location of the foyer area, dimensions (area and volume), atrium location, atrium void dimensions, location of the skylight, finishing materials on the surfaces, and crowd level in the space during the recordings as shown in Table 1. All of these aspects are integrated into the discussions concentrating on the relation between sound environment and the built entity.

\subsection{Characteristics of the case study sites}

Information Commons is a relatively new building compared with the other two libraries. The main foyer area is located on the first floor and is larger than the other two library foyers. The circulation elements and atrium void are directly linked with one another and with the main foyer area. In the Western Bank library, the main foyer area is located on the first floor linked with the circulation stairs, above the atrium void. St. George's library is the oldest building (brick facade) among the three. The interior has been refurbished to provide a modern library for students. As in the other two libraries, the reception area is on the side, but the stairs, located in front of the entrance, dominate the space. The ground floor foyer area is located beneath the atrium void.

In terms of the two-dimensional formal organisation, the "Information Commons" (IC) library has an L-shaped plan, whereas both "Western Bank" (WB) and "St. George's" (SG) libraries are rectangular in layout. The dimensions are crucial for the assessment of the spatial characteristics because they are the most effectual properties within an enclosure for determining the sonic environment and the contextual perception. One other important feature is the location of the foyer space. In SG, it is located at the entrance level, which means that people pass through the main foyer to travel between the other spaces in the library. In IC, the foyer is located on the first floor, and in $\mathrm{WB}$, it is located on the second floor.

IC has the largest area and volume, followed by WB and SG as noted in Table 1. Although the areas in square metres do not differ significantly, the volumes 
Table 1. Spatial and architectural analysis of Western Bank library (WB), Information Commons library (IC), and St. George's library (SG).

\begin{tabular}{|c|c|c|c|c|}
\hline Factors & $\begin{array}{l}\text { Individual } \\
\text { aspects }\end{array}$ & IC & WB & SG \\
\hline \multirow{2}{*}{ Dimensions } & Area & $372 \mathrm{~m}^{2}$ & $368 \mathrm{~m}^{2}$ & $362 \mathrm{~m}^{2}$ \\
\hline & Volume & $2,667 \mathrm{~m}^{3}$ & $1,945 \mathrm{~m}^{3}$ & $1,548 \mathrm{~m}^{3}$ \\
\hline \multirow{3}{*}{ Formal Organisation } & Plan type & $\begin{array}{l}\text { Grid } \\
\text { (l-shape) }\end{array}$ & $\begin{array}{l}\text { Linear } \\
\text { (rectangular) }\end{array}$ & $\begin{array}{l}\text { Linear } \\
\text { (rectangular) }\end{array}$ \\
\hline & Plan order & Common enclosure & Common enclosure & Common enclosure \\
\hline & Plan layout & Basic & Basic & Basic \\
\hline \multirow{3}{*}{ Unit Associations } & Relation & $\begin{array}{l}\text { Spaces linked } \\
\text { by a common space }\end{array}$ & Adjacent & $\begin{array}{l}\text { Spaces linked } \\
\text { by a common space }\end{array}$ \\
\hline & Reference & Interpenetration & Juxtaposition & Interpenetration \\
\hline & Containment & Domain & Cells & Domain \\
\hline $\begin{array}{l}\text { Whole-body } \\
\text { Complementation }\end{array}$ & System & Subordinated & $\begin{array}{l}\text { Spaces bordering } \\
\text { each other }\end{array}$ & Subordinated \\
\hline \multirow{4}{*}{ Spatial Elements } & Foyer location & 1st floor & 2nd floor & Entrance \\
\hline & Atrium location & Above $\mathrm{h}: 14 \mathrm{~m}$ & Below $h: 4 \mathrm{~m}$ & Above $\mathrm{h}: 10.5 \mathrm{~m}$ \\
\hline & Atrium void & $1,638 \mathrm{~m}^{3}$ & $105.5 \mathrm{~m}^{3}$ & $424 \mathrm{~m}^{3}$ \\
\hline & Glass skylight & Above atrium & Above atrium & Above atrium \\
\hline \multirow{3}{*}{ Materials } & Wall material & $\begin{array}{l}\text { Plaster \& wooden } \\
\text { acoustic panels }\end{array}$ & $\begin{array}{l}\text { Wood panels \& glass } \\
\text { sheets }\end{array}$ & Painted brick block \\
\hline & Ceiling material & Acoustic tiles & Hard semi-acrylic & Painted concrete \\
\hline & Floor material & Carpet & Vinyl & Carpet \\
\hline Usage (mean) & Crowd level & 40-Pass, 65-Still & 22-Pass, 14-Still & 25-Pass, 10-Still \\
\hline
\end{tabular}

${ }^{*}$ Differentiated aspects among the three case sites are emphasised with italic characters.

vary greatly. The main reasons for this difference are the location and dimensions of the atrium void. IC has the largest atrium void, measuring 1,638 cubic metres, whereas SG's atrium void measures 424 cubic metres and that of WB measures 105.5 cubic metres. The location of the atrium is also important for sound analysis. In WB, which has the smallest atrium void, the atrium is located below the foyer space, with a height of $4 \mathrm{~m}$. In the other two libraries, the atrium is located above the foyer space, with heights of $10.5 \mathrm{~m}$ in SG and $14 \mathrm{~m}$ in IC.

The aspects of each built entity factor that are present in the case study sites are highlighted in Fig. 4. The spatial relations in IC and SG are similar compared with WB. IC and SG both have similar "relation", "reference", and "containment" characteristics. Spaces are linked by a common space, which is the "atrium" that acts as the main circulation artery for IC and SG, whereas in WB, spaces are adjacent to each other. In IC and SG, interpenetration is the spatial "reference", whereas in WB, it is juxtaposition. Fi- nally, the form of "containment" in IC and SG is the domain, but for WB, it is the arrangement of different cells within the domain. Additionally, the whole-body complementation analysis of IC and SG shows that the main space subordinates the other spaces with the presence of an interpenetrating foyer area. In contrast, in WB, the spaces border each other, and this system is formed by the separately enclosed adjacent unit spaces. The architectural variances and spatial characteristics in each case space lead to differentiated sound formations and overall indoor environments that are discussed within the scope of this study.

In addition to the varying architectural characteristics, materials are crucial for the formation of different sound phenomena that are evaluated in the sound environment analysis. The objective parametric analyses of the indoor acoustic environment for indoor soundscape studies should also consider the material properties such as absorption coefficients similar to the studies in the field of building acoustics. The absorption coefficients of the materials used in all three case 
a)

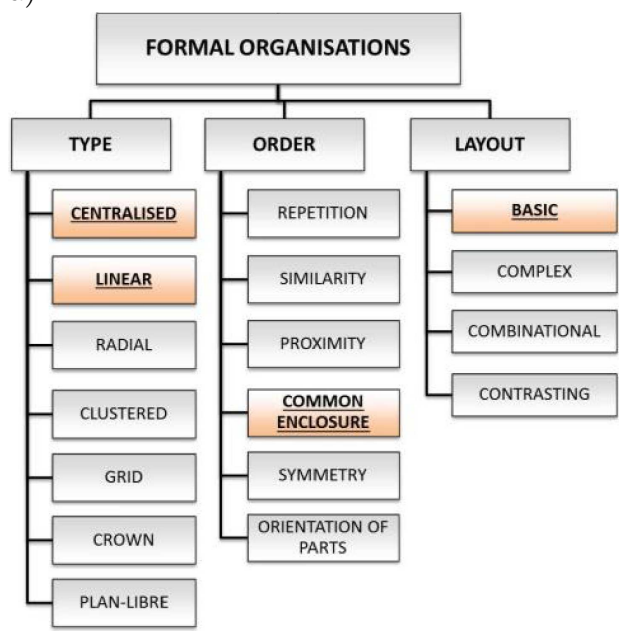

b)

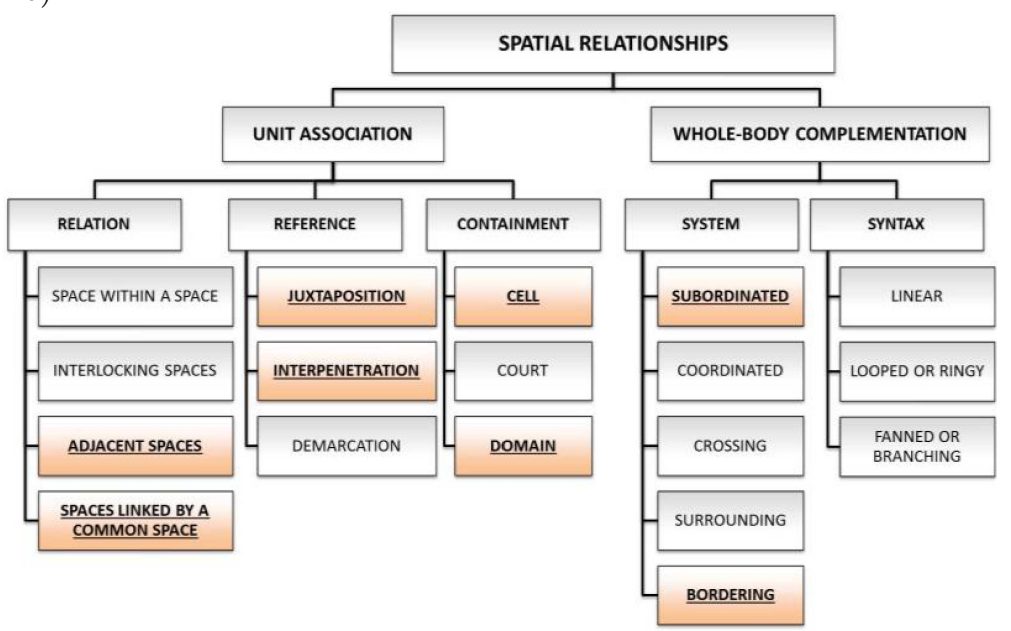

Fig. 4. The aspects of built entity factors; a) formal organisation and b) spatial relationships, analysed in the case study sites.

spaces are identified in Table 2. The finishing materials in the foyer space in IC are wood cladding on the walls (designed as acoustic panels) and carpet flooring made of materials classified with higher absorption coefficients, especially in the mid- and high-frequency ranges. There is a high skylight ceiling over the atrium void and a suspended ceiling over the lower parts, leading to air absorption. In addition, there are several soft, padded sofas around the main space that contribute to the overall sound absorption in the environment. In the foyer of IC, the absorption quality of the finishing materials, especially on the floor and sofas, is higher than in the other two.
The materials used in WB are wooden cladded walls with integrated windows, vinyl flooring, and acrylic panels on the suspended ceiling. There are several leather sofas in the study space. The materials used in the foyer space of WB can be classified as absorbers of the low- to medium-frequency range. Finally, the materials in the foyer of SG are painted brick walls and integrated windows, painted concrete for ceilings and carpet on the floor. Wooden tables and padded chairs are the main furniture items that are present in the main space. In addition, although the highest crowd level is identified in IC, it should be noted that the case spaces are libraries, and in such

Table 2. Absorption coefficients of the materials used in the case sites.

\begin{tabular}{|c|c|c|c|c|c|c|}
\hline Materials used in case sites & $125 \mathrm{~Hz}$ & $250 \mathrm{~Hz}$ & $500 \mathrm{~Hz}$ & $1 \mathrm{kHz}$ & $2 \mathrm{kHz}$ & $4 \mathrm{kHz}$ \\
\hline \multicolumn{7}{|l|}{ Floor Materials } \\
\hline 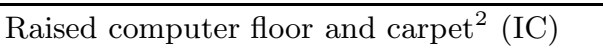 & 0.27 & 0.26 & 0.52 & 0.43 & 0.51 & 0.58 \\
\hline Vinyl tile or linoleum on concrete ${ }^{2}(\mathrm{WB})$ & 0.02 & 0.02 & 0.04 & 0.05 & 0.05 & 0.10 \\
\hline${\text { Carpet on } \text { concrete }^{1}(\mathrm{SG})}$ & 0.02 & 0.06 & 0.14 & 0.37 & 0.60 & 0.65 \\
\hline \multicolumn{7}{|l|}{ Ceiling Materials } \\
\hline Acoustic ceiling tiles $^{1}$ (IC) & 0.05 & 0.22 & 0.52 & 0.56 & 0.45 & 0.32 \\
\hline $4 \mathrm{~mm}$ glass $^{2}(\mathrm{WB})$ & 0.30 & 0.20 & 0.10 & 0.07 & 0.05 & 0.02 \\
\hline Smooth concrete, painted or glazed ${ }^{2}(\mathrm{SG})$ & 0.01 & 0.01 & 0.01 & 0.02 & 0.02 & 0.02 \\
\hline \multicolumn{7}{|l|}{ Wall Materials } \\
\hline Acoustic timber wall panelling $^{2}$ (IC, WB) & 0.18 & 0.34 & 0.42 & 0.59 & 0.83 & 0.68 \\
\hline Unglazed \& painted brick $^{1}(\mathrm{SG})$ & 0.01 & 0.01 & 0.02 & 0.02 & 0.02 & 0.03 \\
\hline Large panes of heavy plate glass $^{2}$ (IC) & 0.18 & 0.06 & 0.04 & 0.03 & 0.02 & 0.02 \\
\hline Ordinary window glass ${ }^{1}$ (SG, WB) & 0.35 & 0.25 & 0.18 & 0.12 & 0.07 & 0.04 \\
\hline \multicolumn{7}{|l|}{ Other } \\
\hline Fully occupied, fabric upholstered ${ }^{2}$ & 0.60 & 0.74 & 0.88 & 0.96 & 0.93 & 0.85 \\
\hline People (adults) ${ }^{1}$ & 0.25 & 0.35 & 0.42 & 0.46 & 0.5 & 0.5 \\
\hline
\end{tabular}

${ }^{1}$ http://www.bembook.ibpsa.us/index.php?title=Absorption_Coefficient

${ }^{2}$ http://www.acoustic.ua/st/web_absorption_data_eng.pdf 
spaces, human-related sound, such as talking, rarely dominates the overall environment. Therefore, it is expected that people do not act as sound sources but rather as receivers, so an increased number of people hypothetically supports the overall sound absorption qualities of the space.

\subsection{Sound recordings}

The sound environments in the three libraries are recorded to analyse the present parametric situation in the identified case locations. The equipment used for the objective assessments is a scientific portable binaural headset-microphone recording system. The recording height is maintained at $165 \mathrm{~cm}$, and the binaural system is placed at least $150 \mathrm{~cm}$ away from any reflecting surfaces or boundaries. The audio samples are then analysed by psychoacoustic analysis software.

The recordings are captured in the foyer areas of all three libraries to thoroughly discuss the spatial factors considering the specific characteristics of each case. The sound environment of each foyer area is sampled for $15 \mathrm{~min}$ on different days in three time slots - morning, noon, and afternoon - as shown in Table 3. A total of nine, $15 \mathrm{~min}$ long individual sound samples are post-analysed by special acoustical analysis software, ArtemiS suite. Thus, in each three-case site; 45 min long sound samples that include data from the morning, noon, and afternoon have been considered. The sound and visual notes at each measurement point along with the "usage frequency", "crowd level", and "number of people passing through" are noted for further assessment of the sound environment at each location. Physical factors such as the sound event variation, duration, time, intensity, level, fluctuation, spectral distribution, acoustic parameter (sound pressure level-SPL, A-weighted, linear), and psychoacoustic parameter (loudness - N) are considered for this study. The two parameters - sound pressure level and loudness - are commonly used parameters for noise annoyance and soundscape studies to describe the sound environment. However, both lack coherence because they are objective parameters and usually should be supported by the subjective findings through questionnaires or survey analysis. In this study, these two parameters are specifically chosen to be analysed together to understand whether they show a variance and also to observe their differentiation (if there is one) from the "effect of architectural factors on sound" perspective.

Table 3. Recording design for case sites based on 3 interchanging sets and 3 time slots.

\begin{tabular}{|c|c|c|c|}
\hline Time slots & SET-1 & SET-2 & SET-3 \\
\hline Morning & WB & SG & IC \\
\hline Noon & IC & WB & SG \\
\hline Afternoon & SG & IC & WB \\
\hline
\end{tabular}

\section{Correlation between Sound environment and built entity factors}

\subsection{Sound environment and crowd level}

First, to examine the relationships between crowd level and sound pressure level (SPL) and between crowd level and loudness $(\mathrm{N})$ in all three libraries, "Spearman's Rho correlation" is used. This nonparametric statistical test has been chosen to measure the strength of association between the two variables and is calculated by the formula shown in Eq. (1). In this test, Spearman's rho $\left(r_{s}\right)$ numerically measures the strength of association between these two variables as 1 (very strong) and 0 (no association). The significance $(p)$ shows the strength of co-occurrence level.

$$
1-\left(\frac{6 \sum d^{2}}{n\left(n^{2}-1\right)}\right) .
$$

The statistical analysis shows that there is a significant positive correlation between crowd level and $\mathrm{SPL}\left(r_{s}=.716, p<.001\right)$, and $\mathrm{N}\left(r_{s}=.7, p<.001\right)$, highlighting the tendency for all considered parameters to increase with an increase in the number of people occupying and using the case study spaces. The relationship was also presented by regression analyses $\left(\mathrm{R}^{2}\right)$ as shown in Fig. 5.

a)

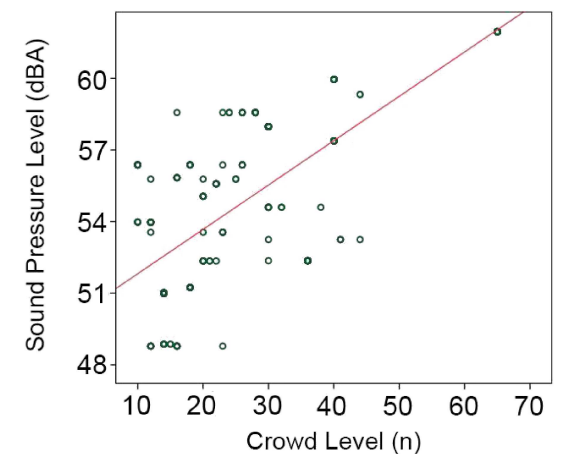

b)

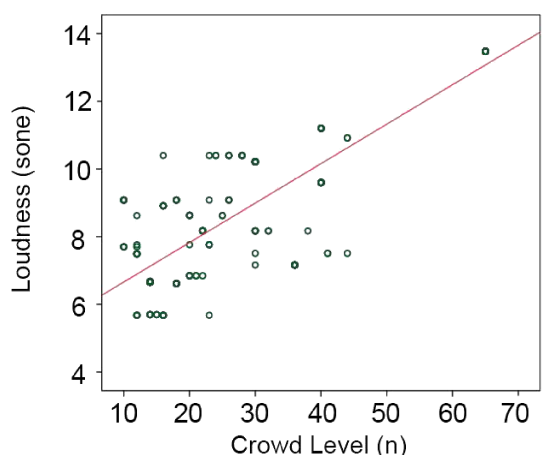

Fig. 5. Scatterplot including the regression lines showing the positive correlation between a) crowd level and sound pressure level - SPL $\left(\mathrm{R}^{2}=0.59\right)$,

b) crowd level and loudness $-\mathrm{N}\left(\mathrm{R}^{2}=0.688\right)$.

In addition, one-way analysis of variance (ANOVA) is used to indicate the differences in the means of 
the test groups. The difference is expressed by the $F$ ratio, which is the ratio of two mean square values of the test groups and is expected to be close to 1 . ANOVA alone lacks the ability to distinguish the groups between which the differences are occurring. Therefore, a Bonferroni post hoc test is also used for further analysis to determine the significance levels $(p)$. ANOVA with Bonferroni post hoc results demonstrates the differences among the means of the test groups (sound pressure level - SPL and loudness $\mathrm{N}$ at different crowd levels), and the different means are identified for the three compared crowd level groups (low-high, low-medium, high-medium). The effect of crowd level (here considered as the number of people) on change in sound pressure level is statistically significant $(\mathrm{F}(2,267)=39.36, p<.001)$. When a Bonferroni adjustment was made for the number of comparisons, all three differences were identified as significant. The statistical tests and their results highlight that crowd level as the indoor environmental factor under the built entity variable affects sound pressure level as one of the physical factors, and loudness - $\mathrm{N}$ has an effect under the sound environment variable among the psychoacoustic factors. Although humans in library spaces are expected to act as absorbers, human-related activities are found to increase both analysed parameters, SPL and $\mathrm{N}$.

\subsection{Effects of spatial factors on the sound environment}

One-way ANOVA and the Bonferroni post hoc test are used to demonstrate the differences among the means of the test groups (sound pressure level-SPL and loudness- $\mathrm{N}$ in different libraries), and the differing means are identified for the three compared library groups: Western Bank-Information Commons (WBIC), Western Bank-St. George's (WB-SG), and Information Commons-St. George's (IC-SG) as shown in Table 4. The effect of the differing architectural characteristics among the case spaces on changing SPL and $\mathrm{N}$ are found to be statistically significant. When a Bon- ferroni adjustment is made for the number of comparisons, all comparisons are identified as significant on two levels. First, significant differences are identified between the mean sound pressure level (SPL) in WB and in IC $\left(p_{\text {Bonf }}<.001\right)$. The mean SPL value of IC is significantly greater than those of WB and SG. In addition, the effect of differing architectural characteristics and spatial factors on changing loudness is statistically significant for all library comparisons $(p<.001)$, with the mean values showing the relation of $\mathrm{WB}<$ $\mathrm{SG}<\mathrm{IC}$.

With respect to the above findings, architectural and spatial characteristics of the case spaces should be evaluated from the indoor soundscape perspective. It should be highlighted that, through a different soundscape evaluation perspective, architectural characteristics should be included for such sound environment analysis. The spatial relations in IC show significant differences as compared with WB, yet are in some ways similar to SG. Even with the significant variations regarding volume, dimensions, material usage, and absorption efficiency values in both IC and SG, SPL, and $\mathrm{N}$ values show similar increasing patterns as compared with WB. Unit association factor is one of the key architectural characteristics that should be evaluated for indoor sound environment results. In both IC and SG, the overall spaces are linked by a common space, which is the "atrium", the referencing of overall spaces are interpenetration, and the overall library space contains all other cells within a common domain. These architectural traits lead to a sound environment with comparatively higher SPL and $\mathrm{N}$ values because the spatial design itself cannot limit or attenuate sonic formations. In contrast, spaces in WB are adjacent to each other and thus divided or bordered by vertical and horizontal planar elements. Juxtaposition is the spatial "reference" for the arrangement of different cells within the domain, so the spaces border each other, which helps isolate sound environments in each separate space.

The second statistical analysis involves two-way ANOVA testing, and the values are shown in Table 5.

Table 4. One-way ANOVA test across the three libraries for varying SPL and N values.

\begin{tabular}{|c|c|c|c|c|c|c|c|c|}
\hline & \multicolumn{3}{|c|}{ Libraries } & \multirow{3}{*}{$F$} & \multirow{3}{*}{$p$} & \multirow{2}{*}{\multicolumn{3}{|c|}{$\begin{array}{l}\text { Comparisons of Libraries } \\
- \text { Bonferroni Adjusted } p\end{array}$}} \\
\hline & \multirow{2}{*}{$\frac{\mathrm{WB}}{\text { Mean } \pm \mathrm{SD}}$} & \multirow{2}{*}{$\frac{\mathrm{IC}}{\text { Mean } \pm \mathrm{SD}}$} & \multirow{2}{*}{$\frac{\mathrm{SG}}{\mathrm{Mean} \pm \mathrm{SD}}$} & & & & & \\
\hline & & & & & & WB-IC & WB-SG & IC-SG \\
\hline SPL (dBA) & $51.34 \pm 2.02$ & $57.82 \pm 3.74$ & $56.48 \pm 1.94$ & 143.96 & 0.001 & 0.001 & 0.001 & 0.003 \\
\hline N (sone) & $6.80 \pm 0.93$ & $10.40 \pm 2.50$ & $9.17 \pm 1.21$ & 104.5 & 0.001 & 0.001 & 0.001 & 0.001 \\
\hline
\end{tabular}

Table 5. Two-way ANOVA test on the interactions of libraries and time slot for varying SPL and $\mathrm{N}$ mean values.

\begin{tabular}{|c|c|c|c|c|c|c|}
\hline \multirow{2}{*}{} & \multicolumn{2}{|c|}{ Library Effect } & \multicolumn{2}{c|}{ Time Slot Effect } & \multicolumn{2}{c|}{ Library*Time Slot Effect } \\
\cline { 2 - 7 } & $F$ & $p$ & $F$ & $p$ & $F$ & $p$ \\
\hline SPL & 582.42 & 0.001 & 255.59 & 0.001 & 77.01 & 0.001 \\
\hline Loudness & 699.98 & 0.001 & 437.71 & 0.001 & 163.01 & 0.001 \\
\hline
\end{tabular}


The results indicate that spatial factors have a significant effect on SPL and N, called the "library effect", as did the indoor environmental factor crowd level, called the "time slot effect", in addition to their interactions. Comparative graphs as shown in Fig. 6 illustrate the significance of the interactions clearly: the noon time slot, which has the highest crowd level, has significantly greater SPL mean values across all libraries compared with the other two time slots, and the morning time slot, which has the lowest crowd level, has the lowest SPL mean values.

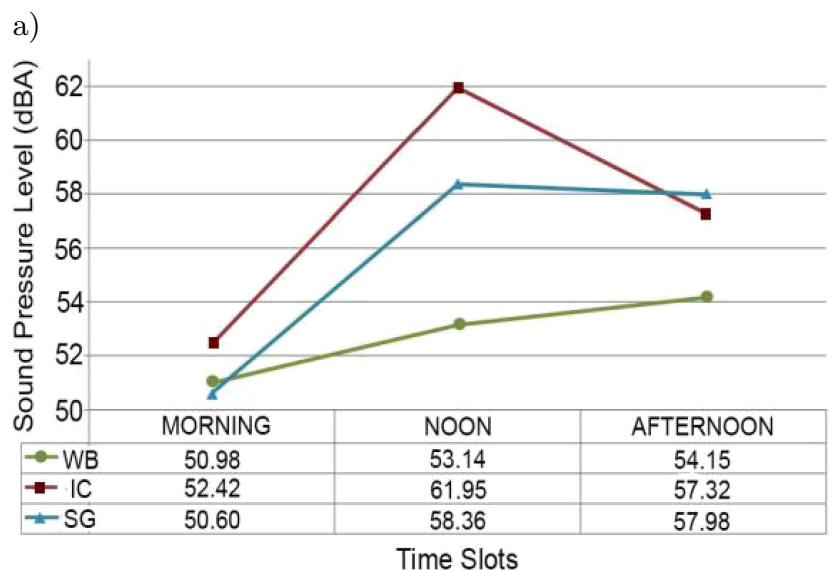

b)

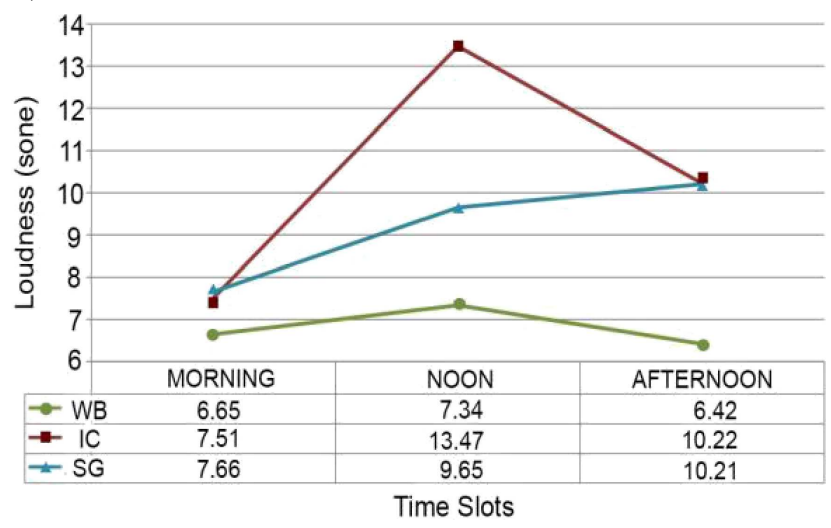

Fig. 6. Two-way ANOVA test on the interactions of WB, IC, and SG libraries and morning, noon, and afternoon time slots for varying a) sound pressure level-SPL, b) loudness-N.

Meanwhile, the largest library space, IC, had higher SPL mean values comparing to $\mathrm{WB}$, as shown in Fig. 6a, where the atrium is located below with a smaller void volume. This is an interesting result when comparing the overall absorption coefficient values. It is identified that even with higher material absorption, varying architectural characteristics may lead to unwanted acoustical formations. When the sound absorption of floor, ceiling, and walls is considered, the highest absorption theoretically occurs in IC (especially for floor absorption) and in WB (especially for ceiling absorption) in ranging frequencies. SG has the lowest absorption characteristics; yet when the SPL and N comparative values among libraries are observed, IC - which has the highest void volume, attenuation, and absorption characteristics - still has high SPL and $\mathrm{N}$ values during different times and crowd levels within a day.

These findings highlight that the differing architectural characteristics and spatial factors under the built entity variable had a significant effect on the parametric results of the sound environment as analysed with regard to SPL and N, as did the indoor environmental factor of crowd, in addition to their interactions. Moreover, it is found that atrium dimension and void volume, unit relations, reference and whole-body complementation system affect sound pressure level and loudness.

\section{Conclusion}

This study brings a new perspective for analysing the overall sound environment of enclosed spaces through the architectural and spatial characteristics that are present in a case space. The significance of each indoor soundscaping variable - (1) sound environment, (2) built entity, and (3) contextual experience - and inputs of all individual factors under each variable have been revealed. The relations among the sound environment and built entity variables are proved through statistical correlations of the case study. It was found that crowd level affects the sound pressure level and the loudness values in the foyer areas of the three library case spaces. The most important findings highlight the relations among the spatial factors and the parametric results. Larger overall spatial volume, atrium void and height lead to higher values in SPL and N parameters. Additionally, higher parametric values were recorded in the spaces where there are spaces linked by a common space, separate units referenced by interpenetration, unit containment with "domain" characteristics, and main space crossing or surrounding other spaces.

\section{References}

1. Arnheim R. (1977), The Dynamics of Architectural Form, UC Press, Berkeley.

2. Bernat S. (2013), Awareness of noise hazards and the value of soundscapes in Polish National Parks, Archives of Acoustics, 38, 4, 479-487.

3. Barkana B.D., Uzkent B. (2011), Environmental noise classifier using a new set of feature parameters based on pitch range, Applied Acoustics, 72, 841-848.

4. Botteldooren D., De Coensel B., De Muer T. (2006), The temporal structure of urban soundscapes, Journal of Sound and Vibration, 292, 105-123. 
5. BRAdley J.S. (2011), Review of objective room acoustics measures and future needs, Applied Acoustics, 72 $713-720$.

6. Brown A.L., Kang J., GJestland T. (2011), Towards standardization in soundscape preference assessment, Applied Acoustics, 72, 387-392.

7. Bruce N.S., Davies W., Adams M.D. (2009), Expectation as afactor in the perception of soundscapes, Acta Acustica united with Acustica, 95.

8. Ching F.D.K. (1996), Architecture: Form, Space and Order, John Wiley \& Sons, New York.

9. Dokmeci P.N. (2013), New framework on indoor soundscaping through built entity, sound environment, and contextual experience, $\mathrm{PhD}$ diss., University of Sheffield.

10. Dokmeci P.N., KAng J. (2010), Objective parameters for acoustic comfort in enclosed spaces, Paper presented at the 20th International Congress on Acoustics, August 23-27, Sydney.

11. Dovey K. (1999), Framing Places: Mediating Power in Built Form, Routledge, London.

12. European Committee for Standardization (2007), Indoor environment input parameters for design and assessment of energy performance of buildings addressing indoor air quality, thermal environment, lighting and acoustics, European Standard EN 15251:2007(E).

13. Genuit K., Fiebig A. (2006), Psychoacoustics and its Benefit for the Soundscape Approach, Acta Acustica united with Acustica, 92, 952-958.

14. Handel S. (1989), Listening: An Introduction to the Perception of Auditory Events, MIT Press, London.

15. Hatfield J., van Kamp I., Job R.F.S. (2006), Clarifying 'Soundscape': Effects of Question Format on Reaction to Noise from Combined Sources, Acta Acustica united with Acustica, 92, 922-928.

16. Hillier B., Hanson J. (1984), The Social Logic of Space, Cambridge, Cambridge University Press.

17. International Organization for Standardization (2006), Building environment design-Indoor environmentGeneral principles, International Standard, ISO 16813, $2006(\mathrm{E})$.

18. Lawson B. (2001), The Language of Space, Architectural Press, Oxford.
19. Liu J., Kang J., Behm H., Luo T. (2014), Effects of landscape on soundscape perception: soundwalks in city parks, Landscape and Urban Planning, 123, 30-40.

20. Meiss P.V. (1990), Elements of Architecture, Van Nostrand Reinhold, New York.

21. Moore B.C.J. (1997), An Introduction to the Psychology of Hearing, Academic Press, London.

22. Norberg-Schulz C. (1971), Existence, Space \& Architecture, Praeger Publishers, New York.

23. Pearson M.P., Richards C. (1994), Architecture and Order: Approaches to Social Space, Routledge, London.

24. Rychtáriková M., Vermeir G. (2011), Soundscape categorization on the basis of objective acoustical parameters, Applied Acoustics, 74, 2, 240-47.

25. Schafer M.R. (1994), The Soundscape: Our Sonic Environment and the Tuning of the World, Destiny Books, Vermont.

26. Thomas P., van Renterghem T., BotteldooREN D. (2011), Using room acoustical parameters for evaluating the quality of urban squares for open-air rock concerts, Applied Acoustics, 72, 210-220.

27. Traux B. (2001), Acoustic Communication, 2nd ed., CT: Ablex, Westport.

28. Traux B., Barrett G.W. (2011), Soundscape in a context of acoustic and landscape ecology, Landscape Ecology, 26, 1201-1207.

29. Tuan Y. (1977), Space and Place: The Perspective of Experience, Edward Arnold Publishers, London.

30. Unwin S. (2003), Analyzing Architecture, Routledge, London.

31. VAN DER LAAN H. (1983), Architectonic Space, E.J. Brill, Leiden.

32. World Soundscape Project (1978), The World Soundscape Project's Handbook for acoustic ecology, The Music of the environment series, Simon Fraser University, and ARC Publications.

33. YAng M., KAng J. (2011), Soundscape analysis using musical features with music information retrieval techniques, Paper presented at Forum Acusticum Conference, Aalborg, June 26-July 1.

34. Zwicker E., FAstl H. (1999), Psychoacoustics: Facts and Models, Springer, New York. 